\title{
Translating Sound Symbolism in Noblesse Comic
}

\author{
Abdurrosyid \\ English Letters Department \\ Syarif Hidayatullah State Islamic University Jakarta, \\ Indonesia \\ abdurrosyideuinjkt.ac.id
}

\author{
Dwi Santika \\ English Letters Department \\ Syarif Hidayatullah State Islamic University Jakarta, \\ Indonesia \\ santika-dwi@gmail.com
}

\begin{abstract}
The study aims at identifying the methods used in translating sound symbolism from English into Bahasa Indonesia. The comics Noblesse by Son Jae Ho is used as the object of analysis. Because the origin of the comics is from South Korea, this paper will also present Korean version (SL1) besides English (SL2) as a means of meaning consideration. Almost 80 data are extracted and nine methods (using adverbs, adjectives, verbs, nouns, idioms, onomatopoeia and mimetic in the target language, explicative phrases, combinations of words and omission or deletion) are identified with additional methods if the proposed methods cannot cove the cases. Each method is analyzed with some examples, considering its accurateness in rendering the meaning of the original expression. The findings are completed with the recommendation for each of the two versions of the translation; the first one is translated by Mank.Id (Comic Online website [TL1]) as the first translator and the other one by the writers (TL2) as the second translators.
\end{abstract}

Keywords - translation method; sound symbolism; comics.

\section{INTRODUCTION}

Comics is a literary and artistic form of art, which is constructed in accordance with the interaction of two semiotic systems - pictures and writings [1]. Comics has found its place in the academic discourse as an interesting subject of study. Herkman [2] states that comics has been assessed from different views, with the focus mostly on the comics itself and its means of expression, its history, or on its roles in society. Examining comics is necessary in order to recognize any characteristics which may have implications for the translation of comics.

Comics is not simply a collection of pictures. Comics, under the umbrella of sequential art, constitutes its own special medium with its own vocabularies, conventions, and uses of symbols. Because comics as a medium shares numerous characteristics with prose, they share many problems when it comes to their translation. Since comics depends on visual language as well as on textual language, it possesses many difficulties unique to its own.

Korea has a great number of onomatopoeic and mimetic expressions. The frequency of their usage in communication varies from situation to situation. For example, the frequency of casual speech is higher than of formal speech. Also, sample uses of onomatopoeic and mimetic expressions are often found in newspapers headline, advertisements, novel and also in comics. Translating onomatopoeic and mimetic words in a comic is one of the hardest tasks for the translator in general. It is hard task for almost everyone to translate these expressions because not all languages have these kinds of expressions. An English onomatopoeic word 'bang-bang' for expressing the sound of a gun being fired, for example, must be translated into another onomatopoeic word that has more or less similar meaning in the translation target language. For such case, Indonesian language has the equivalent word for expressing the same sound in 'dor dor'.

However, not all onomatopoeic words in one language have their equivalent words in other languages certainly because most onomatopoeic or mimetic words are very culturebounded. Therefore, this study shows the list and the analysis of the translation of onomatopoeia and mimetic words from English into Indonesian language. However, due to the original version of the corpus, the writers will equip the analysis with the onomatopoeic and mimetic words of the original version of the comic, i.e. Korean language, in order to be able to check whether the meaning changes or otherwise.

\section{THEORY}

Comics is frequently identified as a visual language [3] and is also considered to have a sociocultural context for 'a structured cognitive system' [4]. Comics is a means of creative expression, a distinct discipline, an art and literary form that deals with the arrangement of pictures or images and words to narrate a story or dramatic idea [5]. Comics is published in many different forms; there are comics in newspapers, magazines, and on web pages of the Internet. Their uses range from entertaining and advertising to informing and teaching. Some features recognized as the most integral parts of comics are the use of both pictures and text to tell a story or a joke. Further details could include panels, speech balloons, a stereotypical cast of characters and various kinds of conventional symbols to indicate such aspects as movements and emotions. Comics without text, can also tell a story.

In addition, Kaindl [6] proposes the following working concept for the purposes of studying the translation of comics. Comics is a narrative form in which the story is told in a series of at least two separate pictures. The individual picture provides context for one another, thus distinguishing comics from a single-frame cartoon. Comics involves linguistic, 
typographic and pictorial signs and combinations of signs as well as a number of specific components such as speechbubbles, speed lines, onomatopoeia etc., which serve particular functions.

Manhwa is the general Korean term for comics and print cartoons. The term usually refers specifically to South Korean comics. The term, along with Manga (in Japanese), is a cognate of the Chinese manhua. Manhwa is inspired by classic Asian arts, especially of Chinese, and have been influenced by the modern history of Korea resulting in a diversity of forms and genres. Distinctive Manhwa can be found in editorial comic strips, artistically oriented works, and web comic serials [7].

As the research corpus, it would look incomplete if the writers do not elaborate the profile of the comics. Noblesse tells a story about a man who fell asleep for 820 years and had slumbered with no knowledge of the mankind's advancement and scientific progress. The land which he once knew has become an unfamiliar place with new technology, attitudes, and lifestyles. Upon his awakening, Cadis Etrama Di Raizel (a.k.a. Rai), seeks to familiarize himself with this era. He locates a loyal servant of his, Frankenstein, who was currently the principal of a South Korean high school. Rai came into a conclusion that this school was the perfect place to help him learn about the modern world. He enrolled and started befriending with a group of good-natured students in order to integrate with the society. This new world was, however, no safer than the previous one; and the dignified, bewildered, technologically awkward Rai discovered himself blended in adventures both ridiculous and dangerous.

The term sound symbolism is defined as certain sounds in the phonetic system of a language that symbolize and denote certain sounds and actions of the natural world. Hinton, Nichols, and Ohala [8] argue that sound symbolism is a systematic relationship between sound and meaning. Then, Brown [9] further suggests and summarizes that sound symbolism is said to be present when a speech sound seems to correlate with an object in the real world. The correlation may take the form of onomatopoeia or mimesis. Sound symbolism is a blanket term used to encompass both imitative (onomatopoeia) and non-imitative words (mimetic).

Pharies [10] suggests that onomatopoeia is a word considered by convention to be acoustically similar to the sound, or the sound produced by the thing to which it refers. Onomatopoeia is a phenomenon that is often associated with comics and it is quite visibly present in a great amount of them. Simply put, onomatopoeia is the formation of words whose sound is imitative of the sound of the noise or action such as hiss, buzz, and bang. Onomatopoeia provides comics with a way of expressing unarticulated sounds of the surrounding world in writing and widens the range of means of expression in comics. In addition, Inose [11] defines onomatopoeia as any words that imitate real sounds, be they human or animal voice or other, for example, Cock-a-Doddle-Doo (imitates the sound of a rooster), and Bang (imitates the sound of a gun). Therefore, onomatopoeia is a part of iconic signs that refers to the object based on the phonic similarities. Also, in graphics and written modality, it signifies the iconic form that resembles the sound- generator [4].

Mimetic word, according to Inose [11], is a word that phonetically expresses states that do not produce sound, such as emotion, a movement or state of things. Kamei [11] states that, between Onomatopoeic and Mimetic words, the mimetic word is a much more distinctive feature as it is not uncommon for English. However, the usage of mimetic words is much more uncommon. Very few languages such as Korean and some African Languages are known to have this type of expression, for example: "sob" (sadness) and "ughh" (frustration). Mimetic generally is defined as gestures of human to communicate messages. Mimetic words are symbolic and iconic that represents sounds, shapes, texture, or something more abstract like feeling and emotion [10]. It has syntactic functions as manner adverbs and refer likely to any aspect of activity such visual and emotion included rather than merely its sound [12].

The studies on the translation of onomatopoeic and mimetic translation normally focus on literary translation. Flyxe [13] identifies nine methods that can be used by translators to translate these expressions: using (1) adjectives, (2) adverbs, (3) verbs (4) explicative paraphrases, (5) onomatopoeia (and mimetic words), and (6) omission. Later, Inose (2008) develops the methods and divides it into nine; 1) translation using adverbs, 2) translation using adjectives, 3) translation using verbs, 4) translation using nouns, 5) translation using explicative paraphrases, 6) translation using idioms 7) translation using onomatopoeic and mimetic expressions, 8) translation with combination or repetition of word, 9) no translation (omission).

\section{METHOD}

The method used in this article is a qualitative method with content analysis as a technique. The writers and also as the second target language translators (TL2) read the unit analysis which is the English version of Noblesse. The writers make a list of onomatopoeic and mimetic words and investigate the equivalents of the words in the Indonesian version of Noblesse, which is translated by the first translator (TL1). The list of onomatopoeic and mimetic words in the English version of Noblesse in comparison with those in the Indonesian version of Noblesse is then analyzed by referring to the original (Korean) version of the comics to obtain a more intensive analysis. The analysis comprises methods used to translate those onomatopoeic and mimetic words, equivalents selected by the first translator (TL1), assessment to those selected equivalents and methods and some alternatives of translation for both onomatopoeic words and mimetic words provided by the second translators (TL2) when inappropriate translations of the first translation (TL1) are found.

\section{RESULT AND DISCUSSION}

\section{A. Onomatopoeia}

1) Translation using onomatopoeic words Chapter 1 No. 3 
There are 10 cases of translating onomatopoeic words by the first translator. In contrast, there are 14 cases of translation using onomatopoeic words in the target language found by the second translators.

The picture in the panels depicts an old coffin that was about to open. Through the word 끼긱 (|kki gik) | the narrator describes the sound of something (caused by heavy thing) that tries to open. In this case, both translators agree to translate the word 끼긱 (kki gik) in SL1 and the word Creak in SL2 which imitates the sound of something rusty with using onomatopoeic in the target language that is "rek".

\section{Chapter 1 No. 12}

In this case, the second translators do not agree with the first translator. The word 휘잉 (hui-ing) in the original version, is translated to "whoosh", both in English and Bahasa Indonesia (online version). While, in TL2, the second translators prefer to use the onomatopoeic word "wusss" to express the sound imitation of wind gusts. The word "wusss" is more familiar and natural with the reader. The translation would be more accurate if the translation itself is natural and acceptable.

\section{Chapter 1 No. 13}

The word 두벅 (du-beok) is an onomatopoeic word that imitates the sound of footsteps. In English version, the first translator uses the word "step" which is equivalent. However, referring TL1 picture in the panel. The first translator does not translate the original expression. The writers do not know the aim of TL1's first translator, whether the person wants to keep foreign (Korean) nuances or deliberately not to translate it. However, in TL2, the second translators chose to use the word "tap tap" that more suitable to describe the sound of footsteps.

\section{Chapter 2 No. 5}

In this case, both translators in English and Bahasa Indonesia (online version) use the same onomatopoeic word to describe the Korean onomatopoeic word 띵 (dding). Referring to the picture, the word "dding" is representing the sound of a bell (traffic lights). To maintain the naturalness of translation, the second translators of TL2 decided to use the word "Ting" which is more familiar to the readers.

\section{Chapter 2 No. 19}

The word 두둥 (du-dung) represents the sound of an explosion (Taylor, 2007). The picture does not tell if there is anything that is going to explode. Yet, it is the aura of the character that looks like someone who holds his anger and is going to scold someone badly. The English translator to describe this uses the word "DOOM!. In Indonesian online version, the translator used the word " $B A B U M$ ". However, the second translators of TL2 chose the word "BUMM!!!" which is equivalent in both meaning and expression.

Chapter 3 No. 7
"HIT" is the word that used by Indonesian translator (online version) to describe the Korean onomatopoeic word 퉁 (thung). The meaning itself represents the sound of something or someone being hit. The word "HIT" does not sound appropriate since the readers are Indonesian people. That is the reason why the second translators (see TL2) use the word " $B U G$ " to express the illustration in the panel.

\section{Chapter 3 No. 16}

In this case, the word 비틀 비틀 (bi-theul bi-tehul) describes the sound of exhaling, blowing or puffing. According to the picture in the panel, the students are feeling tired after running. "Huff Huff" is used by English translator to express this sound. The second translators (see TL2) agree with the English translation and chose to keep using the word "Huff Huff". The Indonesian reader has been familiar with this word. However, in TL1, the translators use the word "Gasp Gasp" which is more suitable for the English readers.

\section{Chapter 5 No. 8}

똑똑 (dduk dduk) is a Korean onomatopoeic word which represents the knocking sound. The context of the picture is, there was a student who knocked on the door. To describe it, in English translation, the translator uses the word "knock knock". While both Indonesian translators (TL1 and TL2), agree to use the word "tok tok tok".

\section{Chapter 9 No. 7}

파바바박 (pha ba ba bak) is an onomatopoeic word that imitates a rattling sound. In English version, the translator uses a noun "clatter". Yet, again, in Indonesian version, both translators agree to use the word "greek Greek"/grak/ which is an Indonesian onomatopoeic word.

\section{Chapter 11 No. 20}

To describe the Korean onomatopoeic word 탁 (thak) which describes a shut sound made by an object, the English translator uses the word "SLAM". While, in Indonesian version (see TL1), the translator leaves the word untranslated and keeps using the original version (Korean language). To fill this gap, the second translations (see TL2) decided to use an Indonesian onomatopoeic word "BRAKK" which has the same meaning with the original expression.

\section{Chapter 12 No.8}

It looks like a coincidence that TL1 uses the same onomatopoeic word as SL1, and TL2 uses the same onomatopoeic word as SL2. The Indonesian translator (see TL1) keeps the word un-translated, while in TL2, the translators use the word "TAK" which corresponds with the English translation and has the same meaning with 탁 (thak) that is a shut sound made by an object.

Chapter 12 No. 12 
후룹 후루룹 (hu-rup hu-ru-rup) is a Korean onomatopoeic word which describes loud sucking sound made by someone when they are eating or drinking something. English has the onomatopoeic word with the same meaning that is "slurp slurp". While, again, in Indonesian translation (see TL1), the first translator uses the original onomatopoeic word and or it means the translator keeps it untranslated. On the other hand, the second translators (see TL2) chose to use the Indonesian onomatopoeic word "sruut sruut".

\section{Chapter 15 No. 15}

In this case, the word 쳇 (chet) is translated into English with an onomatopoeic word "tch" although there is another onomatopoeic word, that also familiar with English reader, that is "Tsk". In TL1, the first translator chooses to use the word "cih" which describes an exclamation of contempt, disdain or impatience of someone. In addition, the word "cuih" has the same meaning and expression as well.

\section{Chapter 20 No. 13}

The Korean onomatopoeic word 부아앙 (bu-a-ang) is an imitation sound of a vehicle (especially a car). Actually, English has this kind of onomatopoeic word that is "broom" while TL1 uses the word "broom". To make it more natural, the second translators in TL2 opt to use the word "bruum". Referring to the panel, the first translator of TL1 changes the layout of the onomatopoeic word, from the left to the right.

\section{2) Translation using noun}

\section{Chapter 9 No. 2}

The word 탁 탁 탁 (thak thak thak) is a Korean onomatopoeic word that shows light knocking sound. To express the same meaning and expression, the first translator in the Indonesian version uses the word "tap tap tap". While, in TL2, the translators choose to use the word "tak tak tak" which is more suitable for the context in the picture.

\section{Chapter 9 No. 8}

딸칵 (ddal khak) is an onomatopoeic word that imitates slight sharp sound (Taylor, 2007). In English version, the translator uses a noun "klick". However, in Indonesian version, both translators agree to use the word "klik" which is an Indonesian onomatopoeic word.

\section{Chapter 9 No. 16}

The Korean onomatopoeic word 파닥 (pha dak) describes someone or something collapse with dull or heavy sound. Just like the context that a student, Han Shin Woo, is hitting his head on the table. To express it, the English translator chooses the word "Flop flop". While, in both Indonesian versions, TL1 and TL2 agree to use a noun "buk buk".

Chapter 11 No. 18

The English translation chose to translate Korean onomatopoeic word 끼 익 (kki-ik) with a noun "screech" which has the same meaning, that is high pitched sound. According to the picture in the panel, the translators (see TL2) choose to use "ciitt" which is a noun in Bahasa Indonesia. On the other hand, the first translator (see TL1) leaves the word untranslated.

\section{Chapter 14 No. 13}

코아직 (Khoa-cik) is a Korean onomatopoeic word that means sound imitation of something crushed into pieces. To describe it, the English translator uses a verb

"Crash". While in TL2, the second translators choose to use a noun "bruk". According to Kamus Besar Bahasa Indonesia (2008), "bruk" means a sound imitation of something heavy falling. On the other hand, the Indonesian translation (online version, see TL1) keeps the word untranslated.

\section{3) Translation using verb}

Chapter 4 No. 18

중얼 중얼 (jung-eol jung-eol) is a Korean onomatopoeic word that indicates a sound of someone who says something unclearly. The English translator uses a verb "mumble mumble". In this case, both Indonesian translators (TL1 and TL2) agree to use a verb "bergumam...".

\section{Chapter 13 No. 14}

"Ba-thump ba-thump" is an English onomatopoeic word used by the translator to describe a Korean onomatopoeic word 두근 두근 (du-geun du-geun) which means sound of a heartbeat. The second Indonesian translators (see TL2) used a verb "Deg". According to Kamus Besar Bahasa Indonesia, the word "Deg" imitates heartbeat sound. Yet, again, the first translator of TL1 (online version) leaves the word untranslated.

\section{B. Mimetic Words}

1) Translation using verb

Chapter 17 No. 24

TABLE 1

TRANSLATING "SIP"

\begin{tabular}{|c|c|c|c|c|}
\hline SL1 & SL2 & TL1 & TL2 & Meaning \\
\hline $\begin{array}{c}\text { 호울짝 } \\
\text { (Ho-ul- } \\
\text { jjag) }\end{array}$ & sip & (Omission) & $\begin{array}{l}\text { Me- } \\
\text { nye- } \\
\text { ruput }\end{array}$ & $\begin{array}{l}\text { Drink } \\
\text { (something) by } \\
\text { taking small } \\
\text { mouthfuls }\end{array}$ \\
\hline
\end{tabular}

Sip (v) is a mimetic word that describes an act of drinking something by taking small mouthfuls.In TL1, the first translator does not translate it, which means the translator in TL1 uses omission. While in TL2, the second translators find the word "menyeruput" (inhale [drinks, water]) as equivalent, which has the same meaning with the word sip. It is a 'straightforward' translation because the translators in TL2 use verb that is exactly alike with the English Translation "sip" which also is a verb. 


\section{2) Translation using noun}

Chapter 16 No. 9

TABLE 2

TRANSLATING "SPARKLE"

\begin{tabular}{|c|c|c|c|c|}
\hline SL1 & SL2 & TL1 & TL2 & Meaning \\
\hline $\begin{array}{c}\text { 사라락 } \\
\text { (sa-ra-rak) }\end{array}$ & sparkle & cling & $\begin{array}{c}\text { kelip } \\
\text { kelip }\end{array}$ & $\begin{array}{c}\text { shine brightly } \\
\text { with flashes of } \\
\text { light }\end{array}$ \\
\hline
\end{tabular}

Sparkle (v) is a mimetic word that describes something shines with flashes of light. In TL1, the first translator uses the onomatopoeic word "cling" which expresses a tinkling sound. While, in TL 2, the second translators decide to use a noun "kelip kelip" which means a small intermittent light, because based on the Korean version (SL1), sa-ra-rak is a mimetic word which points out a movement or situation of the character who seems shining.

\section{3) Translation using adjective}

Chapter 7 No. 12

TABLE 3

TRANSLATING "CLENCH"

\begin{tabular}{|c|c|c|c|c|}
\hline SL1 & SL2 & TL1 & TL2 & Meaning \\
\hline $\begin{array}{c}\text { 뿌 득 } \\
\text { (bbu- } \\
\text { deuk) }\end{array}$ & clench & kepal & $\begin{array}{c}\text { Meng- } \\
\text { genggam } \\
\text { erat }\end{array}$ & $\begin{array}{c}\text { close your } \\
\text { fist tightly }\end{array}$ \\
\hline
\end{tabular}

Clench (v) is a mimetic word that describes someone closes his/her fists tightly. In TL1, the first translator uses a noun "kepal". The meaning is equivalent but it does not match with the picture in the panel. The hand is not tightly closed, but the hand is holding the table tightly. As a result, in TL2, the second translators decide to use "menggenggam erat" that is more accurate.

\section{4) Translation using idiom}

Chapter 8 No. 11

TABLE 4

TRANSLATING "GRIT"

\begin{tabular}{|c|c|c|c|c|}
\hline SL1 & SL2 & TL1 & TL2 & Meaning \\
\hline 뿌 득 & Grit & Grr & Berpikir & Resolve to \\
(ppu- & & & keras & $\begin{array}{c}\text { do } \\
\text { something } \\
\text { deuk) }\end{array}$ \\
& & & & \\
\hline
\end{tabular}

The mimetic word "grit" (n) means courage and determination (Hawker, 2008). In TL1, the first translator uses "Grr" to describe the situation while "Grr" means a state of a person who holds his anger. In TL2, the second translator chooses an equivalent phrase "berpikir keras" which is an idiomatic expression in Bahasa Indonesia. "Berpikir keras" means thinking with maximum effort to figure out the best possible way of getting something that you want.

\section{5) Translation using explicative paraphrase}

Chapter 3 No. 10

"Grin" (v) is a mimetic word that expresses a wide smile.
To solve this, in TL1 the first translator uses a verb "meringis" which means bermuka masam/wajah yang disebabkan rasa tidak suka (frowning). The translation is, thus, not equivalent. Therefore, in TL2, the second translators use "tersenyum sinis" to describe a smile that shows teeth.

TABLE 5

TRANSLATING "GRIN"

\begin{tabular}{|c|c|c|c|c|}
\hline SL1 & SL2 & TL1 & TL2 & Meaning \\
\hline 음 & Grin & $\begin{array}{c}\text { Meringi } \\
\text { (eum) }\end{array}$ & $\begin{array}{c}\text { Tersenyu } \\
\text { m sinis }\end{array}$ & $\begin{array}{c}\text { Smile } \\
\text { Broadly }\end{array}$ \\
\hline
\end{tabular}

6) Omission (no translation)

Chapter 1 No. 14

TABLE 6

OMISSION

\begin{tabular}{|c|c|c|c|c|}
\hline SL1 & SL2 & TL1 & TL2 & Meaning \\
\hline $\begin{array}{c}\text { 펄럭 } \\
\text { (pheol- } \\
\text { reok) }\end{array}$ & Flutter (v) & woosh & - & $\begin{array}{c}\text { fly } \\
\text { unsteadily }\end{array}$ \\
\hline
\end{tabular}

Pheol-reok (v) is a Korean mimetic word to describe something that moves up and down. In SL2, the translator uses a verb "flutter" which shows something that is flying unsteadily (Hawker, 2008) and the translation seems appropriate. In TL1, this mimetic word is left untranslated and keeps using the original language (Korean). While, in TL2, the translators prefer to omit this mimetic word, because the picture on the panel has indicated the movement quite clearly.

\section{7) Translation using mimetic word}

Chapter 9 No. 15

TABLE 7

USING MIMETIC WORD

\begin{tabular}{|c|l|c|c|c|}
\hline SL1 & SL2 & TL1 & TL2 & Meaning \\
\hline $\begin{array}{c}\text { 주 르륵 } \\
\text { (ju reu } \\
\text { reuk) }\end{array}$ & Tear & hiks & hiks & sadness \\
\hline
\end{tabular}

$J u$-reu-reuk (v) is a mimetic word that expresses sadness. In English (SL2), the translator uses a noun "tear" meaning a drop of liquid that falling from a person's eyes (Hawker, 2008). The translators, both in TL1 and TL2 come to an agreement to use the word "hiks" which is familiar with the readers in the Indonesian context to indicate the sadness of someone.

\section{8) Translation with combination}

\section{Chapter 4 No. 2}

샤 샥 (sya-syak) or moving swiftly in SL 2 is a mimetic word that describes a movement. In TL1, the translator used "clingak clinguk". The meaning is not equivalent, because clingak clinguk has a meaning of looking for something or someone. That is why in TL2, the translators use "memperhatikan dengan seksama" which is a combination of a verb and an adjective. 
TABLE 8

COMBINATION

\begin{tabular}{|c|c|c|c|c|}
\hline SL1 & SL2 & TL1 & TL2 & Meaning \\
\hline $\begin{array}{c}\text { 샤 샥 } \\
\text { (sya- } \\
\text { syak) }\end{array}$ & moving & clingak & memperhatikan & Fast \\
clinguk & $\begin{array}{c}\text { dengan } \\
\text { seksama }\end{array}$ & movement \\
\hline
\end{tabular}

\section{CONCLUSION}

Based on the analysis, extracting onomatopoeic words is quite simple, as those are the expressions that imitate real sounds and both English and Indonesian language have these kinds of expression. Yet, extracting mimetic expressions is more complicated as they imitate or express the states, movements, emotions, etc., which do not produce real sounds. So far, the writers also find out that 6 out of 21 onomatopoeic words are left untranslated by the first translator of TL1 (online version). On the other hand, it would be better if the translator uses the target language onomatopoeic or mimetic words as long as the target language has the word that expresses the same or similar meaning. In line with the analysis, the writers come across the term 'straightforward' translation, such as using an adverb, adjective, verb or possible idiom when the translators could find a word (or idiom) in the target language that is equivalent in its meaning to the original onomatopoeic or mimetic word.

All in all, translating the sound symbolism, especially onomatopoeic and mimetic words are not an easy task. Not all languages have both expressions and exact equivalents with acceptable meanings. It becomes a difficult effort for a translator to find the most natural and the closest equivalent to transmitting both the source language's meaning and the expression precisely into the target language.

\section{REFERENCES}

[1] M. Macková, "Specific of Comics Translation," Master's Diploma Thesis, Masaryk University, 2012.

[2] V. Kokko, "KPOW, CHINK, SPLAT: Translation of Sound Effects in Seven Comics," MA Thesis, University of Turku, 2013.

[3] N. Cohn, The Visual Language of Comics: an Introduction to the Structure and Cognition of Sequential Images. New York: Bloomsbury Advances in Semiotics, 2013.

[4] S. A. Guynes, "Four-Color Sound: A Piercean Semiotics of Comic Book Onomatopoeia," vol. 6, no. 1, pp. 58-72, 2015.

[5] Will Eisner, Comics and Sequential Art. United States: Poorhouse Press], 2000.

[6] K. Kaindl, "Thump, Whizz, Boom: A Framework for the Study of Comics under Translation," Target, vol. 11, no. 2, pp. 263-288, 1999.

[7] Boundless, Art History, vol. II: 1400-Present. United States: Boundless, 2013.

[8] L. Hinton, J. Nichols, and J. J. Ohala, (1994) Sound Symbolism, Cambridge: Cambridge University Press. Cambridge: Cambridge University Press, 1994.

[9] E. K. Brown, Encyclopedia of Language \& Linguistics. Boston: Elsevier, 2006

[10] N. Tsujimura, "A Constructional Approach to Mimetic Verbs," in Fried, $M$ \& Boas, H.C., Grammatical Construction: Bact to the roots, Amsterdam: John Benjamins Publishing Company, 2005.

[11] H. Inose, "Translating Japanese Onomatopoeia and Mimetic Words," $2008 . \quad$ [Online]. Available: http://isg.urv.es/library/papers/InoseOnomatopoeia.

[12] J. McCawley, The phonological component of a grammar of Japanese The Hague: Mouton, 1968.
[13] M. Flyxe, Translation of Japanese Onomatopoeia Into Swedish with Focus on Lexicalization. Africa \& Asia 2, 2002. 